\title{
Nebulized dexmedetomidine improves pulmonary shunt and lung mechanics during one-Iung ventilation: a randomized clinical controlled trial
}

\author{
Bo Xu ${ }^{1,2}$, Hong Gao ${ }^{1}$, Dan $\mathrm{Li}^{1}$, Chunxiao Hu ${ }^{\text {Corresp., } 1}$, Jianping Yang ${ }^{\text {Corresp. } 2}$ \\ ${ }^{1}$ Department of Anesthesiology, The Affiliated Wuxi People's Hospital of Nanjing Medical University, Wuxi, Jiangsu, China \\ 2 Department of Anesthesiology, The First Affiliated Hospital of Soochow University, Suzhou, Jiangsu, China \\ Corresponding Authors: Chunxiao Hu, Jianping Yang \\ Email address: huchunxia091211@163.com, szjpyang@126.com
}

Background. Dexmedetomidine (Dex), a selective $\mathrm{a}_{2}$-adrenergic receptor agonist, has been previously reported to attenuate intrapulmonary shunt during one-lung ventilation (OLV) and to alleviate bronchoconstriction. However, the therapeutic effects of nebulized Dex on pulmonary shunt and lung mechanics during OLV have not been evaluated. Here we determine whether nebulized dexmedetomidine improved pulmonary shunt and lung mechanics in patients undergoing elective thoracic surgery in a prospective randomized controlled clinical trial. Methods. One hundred and twenty-eight patients undergoing elective thoracoscopic surgery were included in this study and randomly divided into four groups: $0.9 \%$ saline (Placebo group), $0.5 \mu \mathrm{g} / \mathrm{kg}$ (Dex 0.5 group), $1 \mu \mathrm{g} / \mathrm{kg}$ (Dex ${ }_{1}$ group) and 2 $\mu \mathrm{g} / \mathrm{kg}$ (Dex ${ }_{2}$ group) dexmedetomidine. After bronchial intubation, patients received different nebulized doses of dexmedetomidine $(0.5 \mu \mathrm{g} / \mathrm{kg}, 1 \mu \mathrm{g} / \mathrm{kg}$ and $2 \mu \mathrm{g} / \mathrm{kg})$ or $0.9 \%$ saline placebo during two-lung ventilation(TLV). OLV was initiated $15 \mathrm{~min}$ after bronchial intubation. Anesthesia was maintained with intravenous infusion of cisatracurium and propofol. Bispectral Index values were maintained within $40-50$ by adjusting the infusion of propofol in all groups. Arterial blood gas samples and central venous blood gas samples were taken as follows: 15 min after bronchial intubation during two-lung ventilation ( $\left.T_{L V} V_{15}\right)$, after 30 and 60 min of OLV $\left(\mathrm{OLV}_{30}\right.$ and $\mathrm{OLV}_{60}$, respectively) and $15 \mathrm{~min}$ after reinstitution of TLV (ReTLV). Dynamic compliance was also calculated at $\operatorname{TLV}_{15}, \mathrm{OLV}_{30}, \mathrm{OLV}_{60}$ and ReTLV.

Results. Dex decreased the requirement of propofol in a dose-dependent manner $(P=0.000)$. Heart rate $(H R)$ and mean arterial pressure (MAP) displayed no significant difference among groups ( $P=0.397$ and 0.863$)$. Compared with placebo group, Dex administered between 0.5 and $2 \mu \mathrm{g} / \mathrm{kg}$ increased partial pressure of oxygen $\left(\mathrm{P}_{\mathrm{a}} \mathrm{O}_{2}\right)$ significantly at $\operatorname{OLV}_{30}$ and $\operatorname{OLV}_{60}(P=0.000)$, however Dex administered between 1 and 2 $\mu \mathrm{g} / \mathrm{kg}$ decreased pulmonary shunt fraction $\left(\mathrm{Q}_{s} / \mathrm{Q}_{\mathrm{t}}\right)$ at $\mathrm{OLV} \mathrm{LV}_{30}$ and $\mathrm{OLV}_{60}(P=0.000)$. Compared 
with the placebo group, there were significant increases with dynamic compliance(Cdyn) after OLV in $\operatorname{Dex}_{0.5}, \operatorname{Dex}_{1}$ and $\operatorname{Dex}_{2}$ group $(P=0.000)$. Conclusions. Nebulized dexmedetomidine improved oxygenation not only by decreasing pulmonary shunt but also by improving lung compliance during OLV, which may be effective in managing OLV. 


\section{Nebulized dexmedetomidine improves pulmonary shunt and}

2 lung mechanics during one-lung ventilation: a randomized

\section{3 clinical controlled trial}

4 Bo Xu ${ }^{1,2}$, Hong $\mathrm{GaO}^{1}$, Dan $\mathrm{Li}^{1}$, Chunxiao Hu${ }^{1}$, Jianping Yang ${ }^{2}$

$5{ }^{1}$ Department of Anesthesiology, The Affiliated Wuxi People's Hospital of Nanjing Medical University,

6 Wuxi, Jiangsu, China

$7 \quad{ }^{2}$ Department of Anesthesiology, The First Affiliated Hospital of Soochow University, Suzhou, Jiangsu,

8 China

9

10 Corresponding Author:

11 Chunxiao $\mathrm{Hu}^{1}$

12299 Qingyang road, Wuxi, Jiangsu, 214023, China

13 Email address: huchunxiao91211@163.com

14 Jianping Yang ${ }^{2}$

15188 Shizi Street, Suzhou, Jiangsu, 215006, China

16 Email address: szjpyang@126.com 


\section{Abstract}

27 Background. Dexmedetomidine (Dex), a selective $\mathrm{a}_{2}$-adrenergic receptor agonist, has been

28 previously reported to attenuate intrapulmonary shunt during one-lung ventilation (OLV) and to

29 alleviate bronchoconstriction. However, the therapeutic effects of nebulized Dex on pulmonary

30 shunt and lung mechanics during OLV have not been evaluated. Here we determine whether

31 nebulized dexmedetomidine improved pulmonary shunt and lung mechanics in patients

32 undergoing elective thoracic surgery in a prospective randomized controlled clinical trial.

33 Methods. One hundred and twenty-eight patients undergoing elective thoracoscopic surgery

34 were included in this study and randomly divided into four groups: $0.9 \%$ saline (Placebo group),

$350.5 \mu \mathrm{g} / \mathrm{kg}$ (Dex 0.5 group), $1 \mu \mathrm{g} / \mathrm{kg}$ (Dex 1 group) and $2 \mu \mathrm{g} / \mathrm{kg}$ (Dex 2 group) dexmedetomidine.

36 After bronchial intubation, patients received different nebulized doses of dexmedetomidine $(0.5$

$37 \mu \mathrm{g} / \mathrm{kg}, 1 \mu \mathrm{g} / \mathrm{kg}$ and $2 \mu \mathrm{g} / \mathrm{kg}$ ) or $0.9 \%$ saline placebo during two-lung ventilation(TLV). OLV was

38 initiated 15 min after bronchial intubation. Anesthesia was maintained with intravenous infusion

39 of cisatracurium and propofol. Bispectral Index values were maintained within 40-50 by

40 adjusting the infusion of propofol in all groups. Arterial blood gas samples and central venous

41 blood gas samples were taken as follows: 15 min after bronchial intubation during two-lung

42 ventilation $\left(\mathrm{TLV}_{15}\right)$, after 30 and $60 \mathrm{~min}$ of OLV (OLV 30 and $\mathrm{OLV}_{60}$, respectively) and $15 \mathrm{~min}$

43 after reinstitution of TLV (ReTLV). Dynamic compliance was also calculated at TLV ${ }_{15}, \mathrm{OLV}_{30}$,

$44 \mathrm{OLV}_{60}$ and ReTLV.

45 Results. Dex decreased the requirement of propofol in a dose-dependent manner $(P=0.000)$.

46 Heart rate (HR) and mean arterial pressure (MAP) displayed no significant difference among

47 groups ( $P=0.397$ and 0.863$)$. Compared with placebo group, Dex administered between 0.5 and 2

$48 \mu \mathrm{g} / \mathrm{kg}$ increased partial pressure of oxygen $\left(\mathrm{P}_{\mathrm{a}} \mathrm{O}_{2}\right)$ significantly at $\mathrm{OLV}_{30}$ and $\mathrm{OLV}_{60}(P=0.000)$,

49 however Dex administered between 1 and $2 \mu \mathrm{g} / \mathrm{kg}$ decreased pulmonary shunt fraction $\left(\mathrm{Q}_{\mathrm{s}} / \mathrm{Q}_{\mathrm{t}}\right)$ at

$50 \mathrm{OLV}_{30}$ and $\mathrm{OLV}_{60}(P=0.000)$. Compared with the placebo group, there were significant increases

51 with dynamic compliance(Cdyn) after OLV in $\operatorname{Dex}_{0.5}, \operatorname{Dex}_{1}$ and $\operatorname{Dex}_{2} \operatorname{group}(P=0.000)$. 
52 Conclusions. Nebulized dexmedetomidine improved oxygenation not only by decreasing

53 pulmonary shunt but also by improving lung compliance during OLV, which may be effective in 54 managing OLV.

\section{Introduction}

56 Thoracic surgical procedure frequently requires one-lung ventilation (OLV) to improve the operational field of vision and access to the operative space. However, OLV is commonly associated with hypoxemia due to intrapulmonary shunt in the nonventilated collapsed lung. Hypoxemia, defined as a drop in arterial hemoglobin oxygen saturation $\left(\mathrm{S}_{\mathrm{a}} \mathrm{O}_{2}\right)$, therefore leads to acute hypoxic pulmonary vasoconstriction (HPV) (Cheng et al.,2017). HPV is an important protective mechanism by which blood flow is diverted from the nonventilated lung toward a better-ventilated region, thereby maintaining adequate arterial oxygenation. However, many anesthetics, such as inhalation anesthetics and propofol, have shown positive evidence of inhibiting HPV and increasing hypoxemia (Lumb \& Slinger, 2015).

Dexmedetomidine (Dex)is an $\mathrm{a}_{2}$-adrenoreceptor agonist that has found increasing clinical use for lung protection, for gentle emergence from anesthesia, as an analgesic, as an adjuvant to local anesthetics during regional anesthesia, and even as a supplemental sedative/anxiolytic (Barends et al.,2017; Nguyen et al.,2017). In the last few years, some studies have shown that nebulized Dex administration may allow minimal systemic effects and rapid drug absorption through the respiratory mucosa (Zanaty \& El Metainy,2015; Abdel-Ghaffar et al.,2018). Although nebulized drug administration may be preferred through pulmonary delivery, there are currently no data describing the nebulized effects of Dex on arterial oxygenation during OLV. This study was designed to test the hypothesis that nebulized Dex may improve arterial oxygenation during OLV. Additionally, this study was meant to explore the feasibility of the application of nebulized Dex in OLV during elective thoracic surgery. 
78 This study was a prospective, randomized controlled clinical trial, performed in Wuxi People's

79 Hospital in China. These researcher obtained ethical approval for the study protocol from the

80 Medical Ethics Committee of Wuxi People's Hospital ( Ethical Application Ref:

81 KYuKS201816). This study was registered at the Chinese Ethics Committee of Registering

82 Clinical Trials (ChiCTR1800020112). One hundred and fifty patients undergoing elective

83 thoracoscopic surgery were approached and 128 of them completed the study (Fig. 1). Written

84 informed consent was taken from all participants. The inclusion criteria were as follow: an

85 American Society of Anesthesiologists Physical Status rating of I to II ,aged 20-80 years and

86 height $150-180 \mathrm{~cm}$. Patients with the following conditions were excluded from participation:

87 previous allergic reaction to Dex, serious cardiovascular disorders, liver or kidney dysfunction,

88 arrhythmia, hypertensive patients, severe neuropsychiatric disease, long-term alcohol

89 dependence, or other drug addiction. Patients were randomly allocated into four study groups:

$900.9 \%$ saline (placebo group), $0.5 \mu \mathrm{g} / \mathrm{kg}$ (Dex 0.5 group), $1 \mu \mathrm{g} / \mathrm{kg}$ (Dex 1 group) or $2 \mu \mathrm{g} / \mathrm{kg}$ (Dex

91 group). Randomization was performed by a computer-generated randomization table, with group

92 allocation concealed in sealed opaque envelopes. An anesthesia nurse who was not involved in

93 the research study was tasked with opening the envelopes $1 \mathrm{~h}$ prior to induction of anesthesia and

94 preparation of dexmedetomidine (Jiangsu Hengrui Medicine Co., Ltd) or placebo in identical

95 nebulizer with matching randomization codes. Dexmedetomidine $(0.5 \mu \mathrm{g} / \mathrm{kg}, 1 \mu \mathrm{g} / \mathrm{kg}$ and 2

$96 \mu \mathrm{g} / \mathrm{kg}$ ) was diluted with $0.9 \%$ saline into $5 \mathrm{ml}$ and an equal volume of $0.9 \%$ saline was used as a

97 control in the placebo group. All preoperative and intraoperative management was performed by

98 the same anesthesiologist who was blinded to the study drug. All the data analysis and statistical

99 evaluation was completed by a professional assistant who was blinded to the patient group

100 allocation.

101 Study protocol

102 Patients were monitored by standard monitoring devices upon arrival at the operating room. A

103 22-gauge arterial catheter (Braun Co.) was inserted in the right or left radial artery. A central 
104 venous catheter was placed through the right internal jugular vein and therefore the tip would lie

105 near the right atrium. After anesthesia was induced with midazolam(0.05 mg/kg), sufentanil (0.3-

$1060.4 \mu \mathrm{g} / \mathrm{kg})$, propofol( $1.5-2 \mathrm{mg} / \mathrm{kg})$ and cisatracurium( $(0.15 \mathrm{mg} / \mathrm{kg})$, bronchial intubation was

107 performed with a left-sided double lumen tube (size 37/35 for males and 35/33 for females), then

108 the correct position was confirmed using fiberoptic bronchoscopy. Mechanical ventilation is used

109 in a pressure-controlled mode for protective ventilation during the study. The ventilator

110 parameters were as follow: inspiratory pressure $\left(\mathrm{P}_{\text {insp }}\right) 20 \mathrm{cmH}_{2} \mathrm{O}$, respiratory quotient(I:E) 1:2,

111 oxygen concentration $\left(\mathrm{F}_{\mathrm{i}} \mathrm{O}_{2}\right) 100 \%$ and respiratory rate adjusted to maintain end-tidal carbon

112 dioxide partial pressure $\left(\mathrm{P}_{\mathrm{Et}} \mathrm{CO}_{2}\right)$ between 30 and $35 \mathrm{mmHg} .5 \mathrm{ml}$ of the study drug was

113 immediately administered via the ventilator circuit(Fig. 2) over 10 min after bronchial intubation

114 during two-lung ventilation. OLV was initiated $15 \mathrm{~min}$ after bronchial intubation. During the

115 study, anesthesia was maintained within a bispectral index (BIS) range of 40 to 50 using

116 continuously infused propofol and intermittent administration of cisatracurium. Positive end

117 expiratory pressure (PEEP) to the ventilated lung during OLV was applied in patients who failed

118 to maintain adequate oxygenation $\left(\mathrm{S}_{\mathrm{p}} \mathrm{O}_{2}>92 \%\right)$. Patients requiring PEEP or other recruitment

119 maneuvers for oxygenation were excluded from final analysis. Atropine was administered if

120 heart rate(HR) was less than 50, and ephedrine was required to maintain hemodynamic stability

121 if mean arterial pressure (MAP) had more than $20 \%$ decrease from baseline.

\section{Outcome Measures}

123 Arterial and central venous samples were obtained for blood gas analysis at four time points: 15

124 min after bronchial intubation during two-lung ventilation (TLV $\left.{ }_{15}\right), 30 \mathrm{~min}$ and 60min after OLV

$125\left(\mathrm{OLV}_{30}\right.$ and $\left.\mathrm{OLV}_{60}\right)$ and 15 min after reinstitution of TLV (ReTLV). Pulmonary shunt fraction

$126\left(\mathrm{Q}_{\mathrm{s}} / \mathrm{Q}_{\mathrm{t}}\right)$ was calculated using the following formula:

$127 \mathrm{Q}_{\mathrm{s}} / \mathrm{Q}_{\mathrm{t}}=\left(\mathrm{C}_{\mathrm{c}} \mathrm{O}_{2}-\mathrm{C}_{\mathrm{a}} \mathrm{O}_{2}\right) /\left(\mathrm{C}_{\mathrm{c}} \mathrm{O}_{2}-\mathrm{C}_{\mathrm{v}} \mathrm{O}_{2}\right) \times 100 \%$.

128 Whereby $\mathrm{C}_{\mathrm{a}} \mathrm{O}_{2}$ (oxygen content of arterial blood) $=\left(\mathrm{P}_{\mathrm{a}} \mathrm{O}_{2} \times 0.0031\right)+\left(\mathrm{Hb} \times 1.34 \times \mathrm{S}_{\mathrm{a}} \mathrm{O}_{2}\right)$.

$129 \mathrm{C}_{\mathrm{v}} \mathrm{O}_{2}$ (oxygen content of venous blood $)=\left(\mathrm{P}_{\mathrm{v}} \mathrm{O}_{2} \times 0.0031\right)+\left(\mathrm{Hb} \times 1.34 \times \mathrm{S}_{\mathrm{v}} \mathrm{O}_{2}\right)$. 
$\mathrm{C}_{\mathrm{c}} \mathrm{O}_{2}=\left(\left[\mathrm{F}_{\mathrm{i}} \mathrm{O}_{2} \times\left(\mathrm{PB}-{ }_{\mathrm{p}} \mathrm{H}_{2} \mathrm{O}\right)-\left(\mathrm{P}_{\mathrm{a}} \mathrm{CO}_{2} / \mathrm{RQ}\right)\right] \times 0.0031\right)+(\mathrm{Hb} \times 1.34)$.

$131 \mathrm{~PB}-$ Barometric pressure $(760 \mathrm{mmHg}),{ }_{\mathrm{p}} \mathrm{H}_{2} \mathrm{O}-47 \mathrm{mmHg}$,

$132 \mathrm{Hb}$ - Hemoglobin, RQ - Respiratory quotient (0.8).

133 Dynamic compliance(Cdyn) was obtained from the Primus ventilator at $\mathrm{TLV}_{15}, \mathrm{OLV}_{30}, \mathrm{OLV}_{60}$,

134 and ReTLV. HR and MAP were recorded at these different times.

\section{Statistical analysis}

136 Sample size calculation was based on the difference of $\mathrm{P}_{a} \mathrm{O}_{2}$ by $40 \mathrm{mmHg}$ between groups with a

137 power of $90 \%$ and two-sided a of 0.05 by repeated measures analysis of variance(Lee $e t$

$138 a l ., 2016)$. The enumeration data (gender, ASA and operative site) were measured by $\chi^{2}$ test. Data

139 with normal distributions were presented as mean \pm standard deviation. Intergroup comparisons

140 were determined by LSD test. Variables with repeated measures such as $\mathrm{PaO}_{2}, \mathrm{Cdyn}, \mathrm{Q}_{\mathrm{s}} / \mathrm{Q}_{\mathrm{t}}, \mathrm{HR}$,

141 MAP and BIS were analyzed using repeated measures analysis of variance. All statistical

142 analyses were performed with SPSS version 23.0(IBM Inc., Armonk, NY, USA) and $P<0.05$

143 was considered statistically significant.

\section{Results}

145 Here we enrolled and completed studies of total 128 patients during this study. The CONSORT

146 flow diagram is shown in Fig. 1.

147 Demographic and perioperative data are detailed in Table 1. Overall, there were no differences

148 among groups regarding age $(P=0.960), \operatorname{ASA}(P=0.982)$, gender $(P=0.919)$, weight $(P=0.204)$,

$149 \operatorname{height}(P=0.259)$, operative site $(P=0.988)$, operational time $(P=0.648)$, crystalloid $(P=0.611)$,

150 colloid $(P=0.675)$, urine $(P=0.291), \mathrm{PH}(P=0.978), \mathrm{P}_{\mathrm{a}} \mathrm{O}_{2}(P=0.547), \mathrm{P}_{\mathrm{a}} \mathrm{CO}_{2}(P=0.791)$,

$151 \mathrm{Hb}(P=0.934), \operatorname{FEV}_{1}(P=0.705), \operatorname{FVC}(P=0.417)$ and $\operatorname{FEV}_{1} / \mathrm{FVC}(P=0.809)$.

152 The values of HR, MAP and BIS weren't significantly different among groups ( $P=0.397,0.863$

153 and 0.815 , respectively). During the transition from $\operatorname{TLV}_{15}$ to $\mathrm{OLV}, \mathrm{P}_{\mathrm{a}} \mathrm{O}_{2}$ and Cdyn decreased

154 and $\mathrm{Q}_{\mathrm{s}} / \mathrm{Q}_{\mathrm{t}}$ increased significantly in the four groups $(P=0.000)$. During OLV, $\mathrm{P}_{\mathrm{a}} \mathrm{O}_{2}$ and Cdyn had

155 a significant increase in $\operatorname{Dex}_{0.5}$, Dex ${ }_{1}$ and $\mathrm{Dex}_{2}$ groups compared with the placebo group 
$156(P=0.000)$ while $\mathrm{Q}_{\mathrm{s}} / \mathrm{Q}_{\mathrm{t}}$ decreased in the $\mathrm{Dex}_{1}$ and $\mathrm{Dex}_{2}$ groups compared with the placebo group

$157(P=0.000)$.

158 Patients in the $\operatorname{Dex}_{1}$ and $\mathrm{Dex}_{2}$ group required significantly less propofol during surgery than

159 patients in the placebo group to maintain BIS values between 40 and $50(P=0.000)$ (Tables 2 and

160 3). However, the requirement of sufentanil, cisatracurium, ephedrine and atropine did not differ

161 significantly among groups $(P=0.728,0.204,1.0$ and 1.0 , respectively) (Table 3$)$.

\section{Discussion}

163 Intraoperative hypoxemia can lead to long term complications including end organ failure and

164 increased mortality. One two-center study of a large non-cardiac surgical population estimated

165 that one in fifteen patients experienced hypoxemia for at least 2 minutes and that one in sixty-

166 four patients experienced hypoxemia for a minimum of 5 minutes (Ehrenfeld et al.,2010). The

167 decreased arterial oxygen tension $\left(\mathrm{PaO}_{2}\right)$ may be a reliable indicator of abnormal lung function

168 and predict intraoperative hypoxemia during OLV (Karzai \& Schwarzkopf, 2009). Anesthetics

169 may negatively impact the hemodynamic changes that influence $\mathrm{PaO}_{2}$. For instance, isoflurane

170 and halothane reduce HPV by up to $50 \%$ at 2 MAC and increase the shunt fraction and risk of

171 hypoxia (Saraswat V,2015). Since a majority of intraoperative hypoxemia occurs during OLV,

172 emphasis remains on the discovery and development of appropriate anesthetic agents.

173 Dex was applied to produce a level of sedation during the perioperative period and in

174 mechanically ventilated patients (Chen \& Shen, 2014; Saraswat, 2015). In a recent meta-analysis

175 of 14 randomized controlled trials, Dex was found to increase oxygenation index in seven

176 studies, decrease intrapulmonary shunt in five studies, decrease perioperative HR and MAP in

177 nine studies, and reduce the concentration of the inflammatory factors TNF- $\alpha$ and IL-6 in four

178 studies during OLV (Huang et al.,2017). Intravenous Dex along with isoflurane inhalation was

179 shown to increase $\mathrm{P}_{\mathrm{a}} \mathrm{O}_{2}$ and significantly decrease $\mathrm{Q}_{\mathrm{s}} / \mathrm{Q}_{\mathrm{t}}$ compared to a saline + isoflurane group

180 in a population of adults undergoing elective thoracic surgery (Xia et al.,2013), indicating its

181 safety and feasibility during OLV. 
182 Dex is commonly delivered intravenously but can also be administered as a nebulized

183 premedication in uncooperative children. Inhalation of nebulized Dex is an alternative method of

184 administration, which is related to high bioavailability of Dex (Anttila et al.,2003; McCormick et

185 al.,2008). Nebulized respiratory administration may results in maximizing the surface area of

186 absorption, less drug loss and increased clinical effectiveness (Wolfe \& Braude, 2010). In

187 pediatric populations, it has been demonstrated nebulized Dex (as a premedicant) significantly

188 improved cannulating conditions such as parental separation, face mask acceptance and IV

189 placement (Zanaty \& El Metainy,2015), with no hemodynamic side-effects (Zanaty \& El

190 Metainy,2015; Abdel-Ghaffar et al.,2018). However, these studies were often applied to

191 pediatric populations.

192 In the present study, we evaluated whether nebulized Dex could improve oxygenation in adult

193 patients undergoing thoracic surgery. The major finding of this study was that nebulized Dex

194 increased $\mathrm{P}_{\mathrm{a}} \mathrm{O}_{2}$ during OLV. This is consistent with the results of previous study done by

195 Kerman et al and Xia et al (Kernan et al.,2011; Xia et al.,2013). We surmise this finding may be

196 associated with the fact that intravenous Dex improved oxygenation and improved lung

197 mechanics during OLV. Additionally, there was no marked systemic hemodynamic change in

198 our study. This may be due to the tiny systemic effect of nebulized Dex. In contrast, Nguyen et

$199 a l$. found that intravenous Dex can cause hypotension and bradycardia (Nguyen et al.,2017).

200 Thus, this is especially meaningful as nebulized Dex is superior to standard intravenous route.

201 We also found that $0.5-2 \mu \mathrm{g} / \mathrm{kg}$ nebulized Dex significantly increased dynamic compliance

202 during OLV. These results were in line with intravenous administration in chronic obstructive

203 pulmonary disease (COPD) patients undergoing lung cancer surgery (Lee et al.,2016). Similar

204 results have been reported in a study of morbidly obese patients with restrictive lung disease

205 undergoing bariatric surgery (Hasanin et al.,2018). However, Groeben has been previously

206 reported that inhalation of Dex caused significant bronchoconstriction in an animal study in

207 contrast to intravenous administration (Groeben, Mitzner \& Brown, 2004). This initial 
208 bronchoconstriction is because of a variety of factors. Firstly, aerosols of water generated

209 ultrasonically to provoke bronchoconstriction in persons without asthma (Gonzalez et al., 1994;

210 Groeben et al., 2000). Secondly, the initial bronchoconstriction may result from release of

211 inflammatory mediators on airway smooth muscle or activating reflexes mediated via afferent

212 fibers of the vagus nerve(Gonzalez et al.,1994; Bulut, Hirshman \& Brown,1996). Nevertheless,

213 subsequent bronchodilation can be demonstrated after airway was irritated by aerosolized drugs.

214 Thus, it should be likely that Dex may directly improve oxygenation by stimulating

215 bronchodilation to increase dynamic compliance during OLV, though this remains to be

216 substantiated in future studies.

217 Another finding of this study was that the utilization of nebulized Dex significantly reduced the

218 requirements of anesthetic, specifically propofol. This phenomenon has been previously

219 characterized in intravenous Dex, which decreased the need of isoflurane (Xia et al.,2013) and

220 propofol(Sen et al.,2013) during elective spinal surgery. Although bradycardia and hypotension

221 have been reported in the adult population, patients receiving nebulized Dex did not require more

222 atrophine and ephedrine to maintain adequate hemodynamic stability. Thus it's likely that

223 nebulized Dex may reduce haemodynamic changes related to propofol (Sherman \& Barrick,

224 2019).

225 Interestingly, 1-2 $\mu \mathrm{g} / \mathrm{kg}$ Dex reduced Qs/Qt and improved oxygenation during OLV. This may be

226 due to a variety of factors. Firstly, the attenuation of local inflammation factors contributing to

227 the hypoxic vasodilator effect of OLV may have been influenced by Dex as has been

228 characterized to diminish the production of these pro-inflammatory factors (Zhang et al.,2018;

229 Meng et al.,2018). Secondly, Dex may have played a direct role in pulmonary artery mechanics,

230 promoting the occurrence of HPV by directly impacting bronchodilation (Lee et al.,2016).

231 Finally, reduction in the requirement of propofol, which has been shown to attenuate HPV in a

232 dose-dependent manner, may have contributed to decreased pulmonary shunt and improved HPV 
233 (Huang et al.,2017). All of the above mechanisms are based solely on pathophysiologic

234 speculations and remain to be further ascertained.

235 Despite the novel findings of the present study, there are several limitations to consider. Firstly,

236 this study used central venous samples instead of mixed venous samples as pulmonary catheter

237 placement isn't routine in thoracotomy cases at the participating hospital. However, this

238 technique has been validated and used in many earlier studies (Turnaoglu et al.,2001; Ozcan et

239 al.,2007). Secondly, both left and right thoracotomies and multiple lung pathologies were

240 included in the study. In the future, designing a study aimed at patients with shared trauma and

241 sided thoracotomy may bring to light more accurate results. Thirdly, studies with larger sample

242 sizes are warranted to analyze the safety of nebulized Dex.

\section{Conclusion}

244 Nebulized dexmedetomidine improved oxygenation not only by reducing intrapulmonary shunt

245 but also by increasing lung compliance during OLV. This strategy simultaneously decreased the

246 requirement of propofol without hemodynamic instability. Thus, this study demonstrated that

247 nebulized dexmedetomidine can be used as a feasible strategy for improving oxygenation during

248 OLV in patients undergoing thoracotomy. Nonetheless, studies with larger sample sizes are

249 necessary to clarify the effects and the safety of nebulized Dex used.

\section{Acknowledgements}

251 The authors would like to thank the nurse anesthetists in the operating room of the Wuxi

252 People's Hospital, Jiangsu, Republic of China, for their involvement and support.

\section{References}

254 1. Cheng HY, Croft QPP, Frise MC, Talbot NP, Petousi N, Robbins PA, Dorrington KL. 2017.

255 Human hypoxic pulmonary vasoconstriction is unaltered by $8 \mathrm{~h}$ of preceding isocapnic

256 hyperoxia. Physiol Rep 5(17): e13396 DOI: 10.14814/phy2.13396

257 2. Lumb AB, Slinger P. 2015. Hypoxic pulmonary vasoconstriction: physiology and anesthetic 258 implications. Anesthesiology 122(4):932-46 DOI: 10.1097/ALN.0000000000000569. 
259 3. Barends CR, Absalom A, van Minnen B, Vissink A, Visser A. 2017.Dexmedetomidine 260 versus Midazolam in Procedural Sedation. A Systematic Review of Efficacy and Safety.

261 PLoS One 12(1): e0169525 DOI: 10.1371/journal.pone.0169525

262 4. Nguyen V, Tiemann D, Park E, Salehi A. 2017. Alpha-2 Agonists. Anesthesiol Clin 263 35(2):233-245 DOI: 10.1016/j.anclin.2017.01.009

264 5. Abdel-Ghaffar HS, Kamal SM, El Sherif FA, Mohamed SA. 2018. Comparison of nebulised 265 dexmedetomidine, ketamine, or midazolam for premedication in preschool children undergoing bone marrow biopsy. Br J Anaesth 121(2):445-452 DOI: 10.1016/j.bja.2018.03.039

6. Zanaty OM, E1 Metainy SA. 2015. A comparative evaluation of nebulized dexmedetomidine, nebulized ketamine, and their combination as premedication for outpatient pediatric dental surgery. Anesth Analg 121(1):167-71 DOI: 10.1213/ANE.0000000000000728

7. Ehrenfeld JM, Funk LM, Van Schalkwyk J, Merry AF, Sandberg WS, Gawande A. 2010. The incidence of hypoxemia during surgery: evidence from two institutions. Can J Anaesth 57: 888-897 DOI: 10.1007/s12630-010-9366-5

8. Karzai W, Schwarzkopf K. 2009. Hypoxemia during one-lung ventilation: prediction, prevention, and treatment. Anesthesiology 110: 1402-1411 DOI: 10.1097/ALN.0b013e31819fb15d

9. Saraswat V. 2015. Effects of anaesthesia techniques and drugs on pulmonary function. Indian journal of anaesthesia 59(9):557-64 DOI:10.4103/0019-5049.165850.

10. Chen K, Shen X. 2014. Dexmedetomidine and Propofol total intravenous anesthesia for 281 airway foreign body removal. Ir J Med Sci 183(3):481-4 DOI: 10.1007/s11845-014-1105-4. Dexmedetomidine Improve Arterial Oxygenation and Intrapulmonary Shunt during Onelung Ventilation in Adults Undergoing Thoracic Surgery? A Meta-analysis of Randomized, 
Placebo-controlled Trials. Chin Med J (Engl) 30(14):1707-1714 DOI: 10.4103/00195049.165850

12. Xia R, Yin H, Xia ZY, Mao QJ, Chen GD, Xu W.2013.Effect of intravenous infusion of dexmedetomidine combined with inhalation of isoflurane on arterial oxygenation and intrapulmonary shunt during single-lung ventilation. Cell Biochem Biophys 67 (3):1547-50 DOI: $10.1007 / \mathrm{s} 12013-013-9659-8$.

13. McCormick ASM, Thomas VL, Berry D, Thomas PW. 2008. Plasma concentrations and sedation scores after nebulized and intranasal midazolam in healthy volunteers. Br J Anaesth 100(5):631-6 DOI: 10.1093/bja/aen072

14. Anttila M, Penttilä J, Helminen A, Vuorilehto L, Scheinin H. 2003. Bioavailability of dexmedetomidine after extravascular doses in healthy subjects. Br J Clin Pharmacol 56(6):691-3 DOI: 10.1046/j.1365-2125.2003. 01944. X

15. Wolfe TR, Braude DA. 2010. Intranasal medication delivery for children: a brief review and update. Pediatrics 126(3):532-7 DOI: 10.1542/peds.2010-0616

16. Kernan S, Rehman S, Meyer T, Bourbeau J, Caron N, Tobias JD. 2011. Effects of dexmedetomidine on oxygenation during one-lung ventilation for thoracic surgery in adults. J Minim Access Surg 7(4):227-31 DOI: 10.4103/0972-9941.85645

17. Lee SH, Kim N, Lee CY, Ban MG, Oh YJ. 2016. Effects of dexmedetomidine on oxygenation and lung mechanics in patients with moderate chronic obstructive pulmonary disease undergoing lung cancer surgery. Eur J Anaesthesiol 33(4):275-82 DOI: 10.1097/EJA.0000000000000405 dexmedetomidine infusion on oxygenation and lung mechanics in morbidly obese patients with restrictive lung disease. BMC Anesthesiol 18(1):104 DOI: 10.1186/s12871-018-0572-y 
310 19. Groeben H, Mitzner W, Brown RH. 2004. Effects of the a2-Adrenoceptor Agonist

311 Dexmedetomidine on Bronchoconstriction in Dogs. Anesthesiology 100(2):359-63 DOI:

$312 \quad 10.1097 / 00000542-200402000-00026$

313 20. Gonzalez RM, Bjerke RJ, Drobycki T, Stapelfeldt WT, Green JM, Janowitz MJ, Clark M.

314 1994.Prevention of endotracheal tube-induced coughing during emergence from general

315 anesthesia. Anesth Analg 79(4):792-5 DOI: 10.1213/00000539-199410000-00030

316 21. Bulut Y, Hirshman CA, Brown RH. 1996. Prevention of lidocaine aerosol-induced

317 bronchoconstriction with intravenous lidocaine. Anesthesiology 85(4):853-9 DOI:

$318 \quad 10.1097 / 00000542-199610000-00021$

319 22. Groeben H, Großwendt T, Silvanus MT, Beste M, Peters J. 2000. Lidocaine inhalation for

320 local anesthesia and attenuation of bronchial hyperreactivity with least airway irritation:

321 Effect of three different dose regimens. Eur J Anaesthesiol 17(11):672-9 DOI:

322 10.1046/j.1365-2346. 2000. 00745.x

323 23. Sen S, Chakraborty J, Santra S, Mukherjee P, Das B. 2013. The effect of dexmedetomidine 324 infusion on propofol requirement for maintenance of optimum depth of anaesthesia during elective spine surgery. Indian journal of anaesthesia 57(4):358-363 DOI:10.4103/00195049.118558

327

328

329

330

331

332

333

334

335

24. Sherman JD, Barrick B. 2019. Total intravenous anesthetic versus inhaled anesthetic: pick your poison. Anesthesia and Analgesia 128 (1): 13-15 DOI: 10.1213/ANE.0000000000003898

25. Zhang W, Zhang S, Li B, Sun M, Zhang J. 2018. Paravertebral dexmedetomidine as an adjuvant to ropivacaine protects against independent lung injury during one-lung ventilation: a preliminary randomized clinical trial. BMC Anesthesiol 18(1):67 DOI: 10.1186/s12871018-0532-6.

26. Meng L, Li L, Lu S, Li K, Su Z, Wang Y, Fan X, Li X, Zhao G. 2018. The protective effect of dexmedetomidine on LPS induced acute lung injury through the HMGB1-mediated 
336 TLR4/NF-kB and PI3K/Akt/mTOR pathways. Mol Immunol 94:7-17 DOI:

$337 \quad$ 10.1016/j.molimm.2017.12.008

338 27. Ozcan PE, Sentürk M, Sungur Ulke Z, Toker A, Dilege S, Ozden E, Camci E. 2007. Effects

339 of thoracic epidural anaesthesia on pulmonary venous admixture and oxygenation during

340 one-lung ventilation. Acta Anaesthesiol Scand 51(8):1117-22 DOI: 10.1111/j.1399-

$341 \quad 6576.2007 .01374 . \mathrm{x}$

342 28. Turnaoglu S, Tugrul M, Camci E, Cakar N, Akinci O, Ergin P. 2001. Clinical applicability

343 of the substitution of mixed venous oxygen saturation with central venous oxygen saturation.

344 J Cardiothorac Vasc Anesth 15(5):574-9. DOI: https:// doi.org/ 10.1053/ jcan.2001.26534 
Figure 1

CONSORT flow diagram among four groups

Placebo group, 0.9\% saline. Dex ${ }_{0.5}$ group, $0.5 \mu \mathrm{g} / \mathrm{kg}$ Dex. Dex ${ }_{1}$ group, $1 \mu \mathrm{g} / \mathrm{kg}$ Dex. Dex ${ }_{2}$ group, $2 \mu \mathrm{g} / \mathrm{kg}$ Dex. 


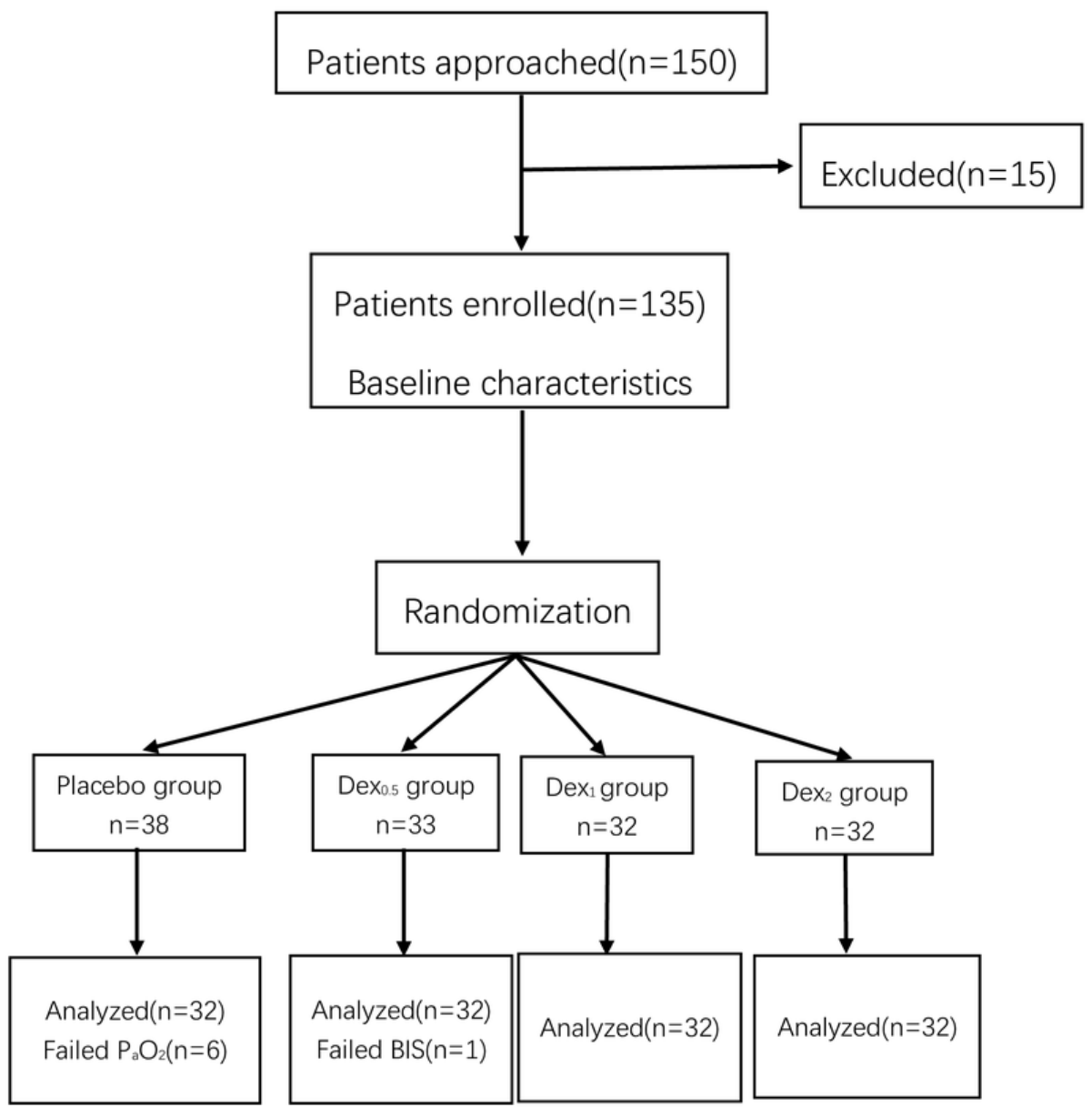


Figure 2

The ventilator circuit

The vibrating mesh nebulizer (Aeroneb Solo, Aerogen, Galway, Ireland) was connected to the circuit with adult T-piece. The devices were placed in the inspiratory limb before the Y-piece.

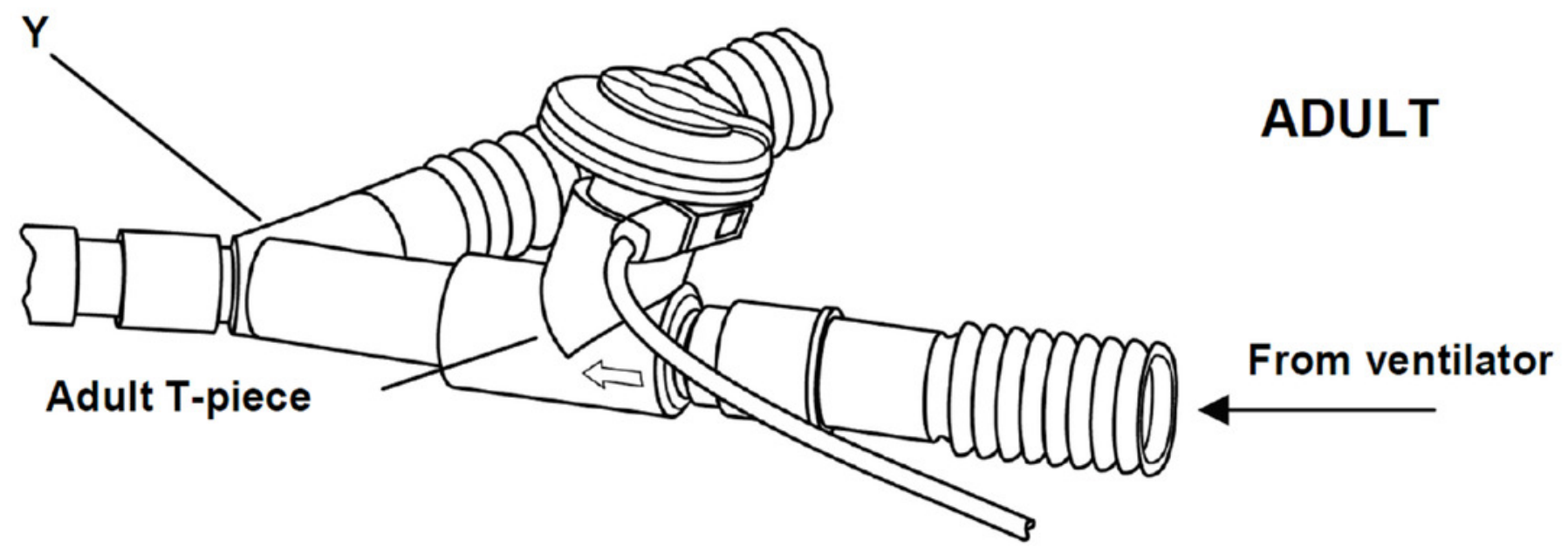




\section{Table 1 (on next page)}

Demographic and perioperative data $(N=32)$

All measurement data are expressed as means \pm SD.

Compared with Placebo group, $* P<0.05$. 


\begin{tabular}{|c|c|c|c|c|c|}
\hline \multirow[t]{2}{*}{ Parameters } & \multicolumn{4}{|c|}{ Groups } & \multirow{2}{*}{$\begin{array}{c}\text { Significance } \\
(P)\end{array}$} \\
\hline & Placebo & $\operatorname{Dex}_{0.5}$ & $\operatorname{Dex}_{1}$ & $\operatorname{Dex}_{2}$ & \\
\hline Age(year) & $55.5 \pm 11.9$ & $55.6 \pm 13.0$ & $56.9 \pm 8.9$ & $56.3 \pm 12.3$ & 0.960 \\
\hline ASA I/II(n) & $27 / 5$ & $26 / 6$ & $27 / 5$ & $27 / 5$ & 0.982 \\
\hline Gender(male/female) & $15 / 17$ & $17 / 15$ & $17 / 15$ & $15 / 17$ & 0.919 \\
\hline Weight $(\mathrm{kg})$ & $62.8 \pm 11.4$ & $65.0 \pm 11.5$ & $60.1 \pm 9.6$ & $60.1 \pm 10.4$ & 0.204 \\
\hline Height(cm) & $164.4 \pm 7.6$ & $167.3 \pm 7.7$ & $165.1 \pm 5.6$ & $164.4 \pm 5.2$ & 0.259 \\
\hline Operative site(Right/Left) & $14 / 18$ & $13 / 19$ & $14 / 18$ & $13 / 19$ & 0.988 \\
\hline Operational time(min) & $117.9 \pm 25.8$ & $116.3 \pm 25.9$ & $112.3 \pm 21.8$ & $111.8 \pm 19.0$ & 0.648 \\
\hline Crystalloid(ml) & $571.9 \pm 172.7$ & $521.9 \pm 131.3$ & $562.5 \pm 164.1$ & $553.1 \pm 158.6$ & 0.611 \\
\hline Colloid(ml) & $440.6 \pm 126.6$ & $462.5 \pm 100.8$ & $435.9 \pm 133.3$ & $425.6 \pm 128.4$ & 0.675 \\
\hline Urine(ml) & $168.1 \pm 38.1$ & $184.1 \pm 43.5$ & $168.1 \pm 53.5$ & $163.4 \pm 45.6$ & 0.291 \\
\hline $\mathrm{PH}$ & $7.41 \pm 0.03$ & $7.41 \pm 0.02$ & $7.40 \pm 0.03$ & $7.40 \pm 0.02$ & 0.978 \\
\hline $\mathrm{P}_{\mathrm{a}} \mathrm{O}_{2}(\mathrm{mmHg})$ & $84.3 \pm 5.8$ & $83.6 \pm 6.3$ & $82.9 \pm 4.8$ & $82.3 \pm 6.2$ & 0.547 \\
\hline $\mathrm{P}_{\mathrm{a}} \mathrm{CO}_{2}(\mathrm{mmHg})$ & $35.3 \pm 1.5$ & $35.3 \pm 1.5$ & $35.2 \pm 1.4$ & $35.0 \pm 1.0$ & 0.791 \\
\hline $\mathrm{Hb}\left(\mathrm{mg} \mathrm{l}^{-1}\right)$ & $117.2 \pm 12.0$ & $117.2 \pm 11.7$ & $118.3 \pm 12.5$ & $118.8 \pm 11.9$ & 0.934 \\
\hline $\mathrm{FEV}_{1}(\%)$ & $80.5 \pm 10.3$ & $82.0 \pm 9.5$ & $79.2 \pm 10.4$ & $80.0 \pm 8.5$ & 0.705 \\
\hline $\mathrm{FVC}(\%)$ & $88.2 \pm 8.5$ & $88.8 \pm 7.8$ & $86.1 \pm 8.9$ & $86.2 \pm 6.9$ & 0.417 \\
\hline $\mathrm{FEV}_{1} / \mathrm{FVC}(\%)$ & $84.3 \pm 8.5$ & $85.6 \pm 8.2$ & $83.7 \pm 8.7$ & $84.0 \pm 7.5$ & 0.809 \\
\hline
\end{tabular}

1 Note:

2 ASA, American society of anesthesiologists physical status; $\mathrm{PH}$, Hydrogen ion concentration; $\mathrm{P}_{\mathrm{a}} \mathrm{O}_{2}$, Arterial oxygen partial pressure;

$3 \mathrm{P}_{\mathrm{a}} \mathrm{CO}_{2}$, Arterial partial pressure of carbon dioxide; Hb, Hemoglobin concentrations; $\mathrm{FEV}_{1}$, Forced expiratory volume in one second;

4 FVC, Forced vital capacity. 


\section{Table 2 (on next page)}

Changes of hemodynamics and respiratory mechanics $(N=32)$

All data are expressed as means \pm SD.

Compared with Placebo group, $* P<0.05$;

${ }^{\mathrm{a} P} P$ value of main effect(group); ${ }^{\mathrm{b} P}$ value of main effect(time); ${ }^{\mathrm{C}} \boldsymbol{P}$ value of crossover effect. 


\begin{tabular}{|c|c|c|c|c|c|c|}
\hline Parameters & Groups & $\mathrm{TLV}_{15 \mathrm{~min}}$ & $\mathrm{OLV}_{30 \text { min }}$ & $\mathrm{OLV}_{60 \min }$ & ReTLV & $P$ value \\
\hline \multirow{6}{*}{$\begin{array}{c}\mathrm{P}_{\mathrm{a}} \mathrm{O}_{2} \\
(\mathrm{mmHg})\end{array}$} & & & & & & $0.000^{\mathbf{b}}$ \\
\hline & Placebo & $431.8 \pm 54.3$ & $168.6 \pm 43.6$ & $178.5 \pm 41.3$ & $402.1 \pm 42.1$ & 0.000 \\
\hline & $\operatorname{Dex}_{0.5}$ & $435.8 \pm 44.1$ & $217.9 \pm 43.5^{*}$ & $255.6 \pm 47.0^{*}$ & $418.7 \pm 33.2$ & 0.000 \\
\hline & $\operatorname{Dex}_{1}$ & $424.5 \pm 38.7$ & $242.5 \pm 60.8^{*}$ & $282.1 \pm 54.6^{*}$ & $405.8 \pm 37.8$ & 0.000 \\
\hline & $\operatorname{Dex}_{2}$ & $423.4 \pm 53.3$ & $262.7 \pm 53.6^{*}$ & $298.6 \pm 38.4^{*}$ & $409.1 \pm 51.6$ & 0.000 \\
\hline & $P$ value & 0.691 & 0.000 & 0.000 & 0.429 & $0.000^{\mathrm{a}}\left(P=0.000^{\mathrm{c}}\right)$ \\
\hline \multirow{6}{*}{$\begin{array}{c}\text { Cdyn } \\
\left(\mathrm{ml} / \mathrm{cmH}_{2} \mathrm{O}\right)\end{array}$} & & & & & & $0.000^{\mathbf{b}}$ \\
\hline & Placebo & $43.4 \pm 7.1$ & $21.0 \pm 2.8$ & $19.7 \pm 2.8$ & $32.4 \pm 2.7$ & 0.000 \\
\hline & $\operatorname{Dex}_{0.5}$ & $42.8 \pm 6.0$ & $26.7 \pm 2.4^{*}$ & $26.2 \pm 2.4^{*}$ & $38.7 \pm 2.6^{*}$ & 0.000 \\
\hline & $\operatorname{Dex}_{1}$ & $42.2 \pm 5.3$ & $26.4 \pm 2.6^{*}$ & $25.5 \pm 2.6^{*}$ & $37.8 \pm 1.8^{*}$ & 0.000 \\
\hline & $\operatorname{Dex}_{2}$ & $41.5 \pm 4.3$ & $26.9 \pm 3.2^{*}$ & $26.2 \pm 2.9^{*}$ & $38.5 \pm 2.5^{*}$ & 0.000 \\
\hline & $P$ value & 0.619 & 0.000 & 0.000 & 0.000 & $0.000^{\mathrm{a}}\left(P=0.000^{\mathrm{c}}\right)$ \\
\hline \multirow[t]{6}{*}{$\mathrm{Q}_{\mathrm{s}} / \mathrm{Q}_{\mathrm{t}}(\%)$} & & & & & & $0.000^{\mathbf{b}}$ \\
\hline & Placebo & $9.9 \pm 2.2$ & $30.4 \pm 2.3$ & $27.5 \pm 1.4$ & $9.5 \pm 0.5$ & 0.000 \\
\hline & $\operatorname{Dex}_{0.5}$ & $9.8 \pm 1.2$ & $30.0 \pm 3.0$ & $27.2 \pm 2.5$ & $9.4 \pm 0.7$ & 0.000 \\
\hline & $\operatorname{Dex}_{1}$ & $9.4 \pm 2.0$ & $24.6 \pm 2.2^{*}$ & $22.3 \pm 3.6^{*}$ & $9.4 \pm 0.6$ & 0.000 \\
\hline & $\operatorname{Dex}_{2}$ & $9.7 \pm 2.3$ & $22.6 \pm 2.5^{*}$ & $21.6 \pm 3.1^{*}$ & $9.8 \pm 0.6$ & 0.000 \\
\hline & $P$ value & 0.789 & 0.000 & 0.000 & 0.112 & $0.000^{\mathrm{a}}\left(P=0.000^{\mathrm{c}}\right)$ \\
\hline \multirow[t]{6}{*}{ HR (bpm) } & & & & & & $0.000^{\mathbf{b}}$ \\
\hline & Placebo & $68.9 \pm 9.3$ & $74.6 \pm 11.4$ & $76.0 \pm 10.3$ & $79.3 \pm 10.9$ & 0.002 \\
\hline & $\operatorname{Dex}_{0.5}$ & $70.4 \pm 11.9$ & $73.6 \pm 13.2$ & $72.8 \pm 12.3$ & $74.3 \pm 13.1$ & 0.640 \\
\hline & $\operatorname{Dex}_{1}$ & $72.1 \pm 10.3$ & $71.6 \pm 11.0$ & $71.0 \pm 11.5$ & $74.9 \pm 9.7$ & 0.478 \\
\hline & $\operatorname{Dex}_{2}$ & $68.3 \pm 8.4$ & $73.0 \pm 10.0$ & $70.3 \pm 8.0$ & $72.6 \pm 9.0$ & 0.121 \\
\hline & $P$ value & 0.424 & 0.772 & 0.143 & 0.086 & $0.397^{\mathrm{a}}\left(P=0.064^{\mathrm{c}}\right)$ \\
\hline \multirow{3}{*}{$\begin{array}{c}\text { MAP } \\
(\mathrm{mmHg})\end{array}$} & & & & & & $0.000^{\mathbf{b}}$ \\
\hline & Placebo & $82.0 \pm 8.2$ & $84.1 \pm 9.5$ & $83.0 \pm 9.2$ & $92.0 \pm 10.2$ & 0.000 \\
\hline & $\operatorname{Dex}_{0.5}$ & $83.3 \pm 10.6$ & $81.5 \pm 9.8$ & $84.4 \pm 8.7$ & $88.3 \pm 9.3$ & 0.043 \\
\hline
\end{tabular}




\begin{tabular}{ccccccc} 
& Dex $_{1}$ & $85.6 \pm 18.1$ & $84.2 \pm 8.5$ & $83.6 \pm 9.3$ & $90.0 \pm 9.1$ & 0.132 \\
& Dex $_{2}$ & $84.7 \pm 6.8$ & $82.2 \pm 11.0$ & $83.0 \pm 9.3$ & $90.7 \pm 10.8$ & 0.002 \\
& $P$ value & 0.633 & 0.611 & 0.914 & 0.502 & $0.863^{\mathrm{a}}\left(P=0.580^{\mathrm{c}}\right)$ \\
& & & & & $0.000^{\mathbf{b}}$ \\
BIS & & & & & 0.000 \\
& Placebo & $45.6 \pm 2.9$ & $43.5 \pm 2.2$ & $44.1 \pm 2.0$ & $47.5 \pm 2.0$ & 0.000 \\
& Dex $_{0.5}$ & $45.4 \pm 2.4$ & $43.2 \pm 2.4$ & $43.9 \pm 2.3$ & $47.2 \pm 1.3$ & 0.000 \\
& Dex $_{1}$ & $45.6 \pm 2.9$ & $43.0 \pm 2.4$ & $44.8 \pm 2.0$ & $47.6 \pm 2.0$ & 0.000 \\
& Dex $_{2}$ & $45.3 \pm 2.8$ & $42.9 \pm 2.2$ & $44.9 \pm 2.3$ & $47.8 \pm 2.5$ & $0.815^{\mathrm{a}}\left(P=0.650^{\mathrm{c}}\right)$ \\
\hline
\end{tabular}

\section{Note:}

$2 \mathrm{TLV}_{15}, 15$ min after intubation during two-lungs ventilation; $\mathrm{OLV}_{30}$, after 30 min of one-lung ventilation; $\mathrm{OLV}_{60}$, after $60 \mathrm{~min}$ of one3 lung ventilation; $\mathrm{P}_{\mathrm{a}} \mathrm{O}_{2}$, arterial oxygen tension $/ \mathrm{mmHg} ; \mathrm{Cdyn}$, dynamic compliance $/ \mathrm{ml} / \mathrm{cmH}_{2} \mathrm{O} ; \mathrm{Q}_{\mathrm{s}} / \mathrm{Q}_{\mathrm{t}}(\%)$, pulmonary shunt fraction/\% 4 ; HR, heart rate/bpm; MAP, mean artery pressure/mmHg; BIS, bispectral index. 


\section{Table 3 (on next page)}

Amount of anesthetic and hemodynamic agents administrated during OLV $(N=32)$

All data are expressed as means \pm SD.

Compared with Placebo group, ${ }^{*} P<0.05$. 


\begin{tabular}{lllllc}
\hline Parameters & \multicolumn{2}{c}{ Groups } & \multicolumn{2}{c}{ Significance } \\
\cline { 2 - 5 } & Placebo & Dex $_{\mathbf{0 . 5}}$ & Dex $_{\mathbf{1}}$ & Dex $_{\mathbf{2}}$ & 0.000 \\
\hline Propofol(mg) & $491.3 \pm 25.6$ & $494.5 \pm 28.3$ & $444.1 \pm 20.8^{*}$ & $388.3 \pm 23.7^{*}$ & 0.728 \\
Sufentanil $(\mu \mathrm{g})$ & $48.3 \pm 6.4$ & $47.5 \pm 6.3$ & $47.0 \pm 5.3$ & $46.8 \pm 5.2$ & 0.204 \\
Cisatracurium(mg) & $24.4 \pm 1.7$ & $24.8 \pm 1.7$ & $24.0 \pm 1.4$ & $24.0 \pm 1.6$ & 1.0 \\
Ephedrine(mg) & $0.3 \pm 1.3$ & $0.3 \pm 1.2$ & $0.3 \pm 1.2$ & $0.3 \pm 1.2$ & 1.0 \\
Atropine(mg) & $0.0 \pm 0.1$ & $0.0 \pm 0.1$ & $0.0 \pm 0.1$ & $0.0 \pm 0.1$ & \\
\hline
\end{tabular}

